Virginia Tech • Virginia State University

\title{
COVID-19: MEDIDAS
}

\section{PREVENTIVAS}

\section{COMO PREPARARSE CONTRA UN BROTE EN SU COMUNIDAD}

Un brote de COVID-19 puede durar por mucho tiempo en su comunidad. Usted puede ayudar a proteger su salud y las de sus seres queridos al crear un plan para su hogar en caso de que haya un brote de COVID-19.

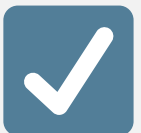

Hable con aquellos que van estar incluidos en su plan. Reúnase con todos los que viven en su hogar, otros familiares y amigos para que hablen de las necesidades de cada uno.

Planifique como van a cuidar de aquellos que pudieran estar en mayor riesgo, incluyendo personas mayores 0 ancianos y personas con condiciones médicas crónicas.

Conozca y hable con sus vecinos acerca de un plan de emergencia.

Así se pueden ayudar unos a otros. Únase a la página de Internet o redes sociales de su vecindad si tienen una.

$\sqrt{10}$ Identifique las organizaciones de ayuda en su comunidad que pudieran darle la información correcta, servicios de salud, servicios de apoyo y otros recursos necesarios.

Haga una lista de números de teléfono en caso de emergencia.

Incluya familiares, amigos, vecinos, sus médicos, hospitales, el departamento de salud local y otros números importantes para usted.

Ponga en práctica acciones preventivas AHORA MISMO. Esto incluye evitar contacto cercano con personas que están enfermas y si usted está enfermo quédese en casa. Cubra su boca cuando tosa o estornuda, limpie/desinfecte superficies que se tocan frecuentemente y lávese las manos.

Escoja en su casa una habitación que se pueda usar para separar de los demás a aquellos que se enfermen. Planifique como limpiar ese cuarto 0 cuartos cuando alguien caiga enfermo. 